\title{
The role of services in the environmental Kuznets curve for Spain
}

\author{
Manuel Cantavella* \\ Departamento de Economía, Instituto de Economía Internacional, Universitat Jaume I, Castellón, Spain \\ Received: 4 October 2019 \\ Revised: 1 March 2020 \\ Accepted: 4 May 2020
}

\begin{abstract}
This paper examines the influence of the service sector in the environmental Kuznets curve (EKC) model regarding carbon dioxide $\left(\mathrm{CO}_{2}\right)$ emissions. The analysis is applied for Spain during the period 1940-2014. It compares the standard environmental Kuznets curve model and its modification by isolating the evolution of the impact of services. The results through the autoregressive distributed-lag (ARDL) estimation strategy confirm that even though all economic activities tend to be more and more sustainable, it is the development of service sector that becomes fundamental in the reduction of per capita $\mathrm{CO}_{2}$ emissions.
\end{abstract}

Keywords: environmental Kuznets curve; service sector; ARDL JEL Classification Codes: O13, Q50

\section{Introduction}

The EKC model explains that some environmental quality indices deteriorate at first as the economy grows in order to improve later as the economy develops. It should happen in the long run and once a certain turning point of a country's economy level is reached. The curve finally adopts an inverted U-shaped pattern. This idea is based on Kuznets' (1955) first hypothesis which asserts that initially economic inequality is larger than later on when the economy develops and inequality tends to be reduced. The EKC had an initial support from some authors towards the end of the last century. Thus, Grossman and Krueger (1991), Shafik and Bandyopadhyay (1992) and Panayotou (1993) provided the first formal evidence about an inverted Ushaped relationship between different pollutants and per capita income. Since then a large number of papers have tested the existence of the EKC for a number of countries, by using different sample periods, control variables and a variety of econometric methods and models. There are some surveys on this phenomenon which offer a comprehensive overview of the state of the question such as Dinda (2004), Kijima et al. (2010) and Pasten and Figueroa (2012). Recent

\footnotetext{
*Corresponding author. E-mail: mcantave@uji.es.

Citation: Cantavella, M. (2020) The role of services in the environmental Kuznets curve for Spain, Economics and Business Letters, 9(4), 326-333.
}

DOI: $10.17811 /$ ebl.9.4.2020.326-333 
reviews are those of Sarkodie and Strezov (2019), and Shahbaz and Sinha (2019). Other interesting studies refer to Balsalobre-Lorente and Alvarez-Herranz (2016a and 2016b).

The evolution of a country's economy can be assessed by using time series data on macro variables such as the gross domestic product (GDP). Thus, the environmental Kuznets invertedU-shaped curve might be found when the performance of an economy and the evolution of, for example, a global pollutant such as $\mathrm{CO}_{2}$ is contemplated in a long-time scope. Most empirical EKC studies use data from 1970 onwards, thus, it is more complicated that data capture a gradual transition from both the agriculture and industry sectors to the tertiary sector. This research focuses on this perspective by employing a date span of about 75 years (1940-2014). The objective, and novelty, of this paper is to examine how changes in the productive structure of Spain affect the standard EKC model. Specifically, we study the role of services on $\mathrm{CO}_{2}$ emissions in comparison to the rest of economic activities. The hypothesis is that the changing GDP structure of a country towards service activities leads to an ever-decreasing environmental impact. The theoretical link that connects the service sector and the evolution of $\mathrm{CO}_{2}$ emissions can be derived from the scale, composition and technical effect that Grossman and Krueger (1991) pointed out. Hence, within the service sector, which includes a wide variety of intangible goods from warehousing and transportation to professional services and health care as well as many others, the scale effect would imply more pollution as more service output is produced. The composition effect would mean a structural change of production going from a materialbased economy to a more information-oriented services. At this stage, $\mathrm{CO}_{2}$ emissions start to mitigate. The composition effect is closely related to the technical effect where cleaner and more efficient technologies help reducing the level of pollution.

The percentage contribution of the service sector to total GDP in Spain grew from 39 percent to 67 percent during the sample period. However, it is important not only to observe the percentage change, given that the service sector uses energy to be into operation, but the quality of that change too. In other words, more information-based services and a less material economy reduce the levels of $\mathrm{CO}_{2}$ emissions. This is usually assumed in the EKC but not proved as such. As far as known, there is just one reference that measures the service effects on $\mathrm{CO}_{2}$ emissions among other variables and is done for the Austrian economy between 1960 and 1999 (Friedl and Getzner 2003). The authors use the growth rate of services although they keep the value of services in the GDP variable, so that services are counted twice. Their estimate is a negative elasticity of 0.36 between services and $\mathrm{CO}_{2}$ emissions. The present paper tries to overcome the double counting and provide a different perspective by comparing the standard EKC model with the modified EKC specification.

\section{Methods}

Studies on the EKC analysis typically assume that the environmental degradation can be expressed as a quadratic function of GDP. The standard econometric specification is the following:

$$
c_{t}=\beta_{0}+\beta_{1} y_{t}+\beta_{2}\left(y_{t}\right)^{2}+e_{t}, \quad t=1940 \ldots 2014
$$

where $c_{t}$ is the per capita $\mathrm{CO}_{2}$ emissions, $y_{t}$ is the per capita GDP and $e_{t}$ is the error term which is assumed to be independent and normally distributed. All variables are taken in natural logarithms so that elasticities can be easily interpreted. According to the standard EKC form, we would expect that the elasticity of $\mathrm{CO}_{2}$ with respect to per capita GDP be positive $\left(\beta_{1}>0\right)$ and the per capita GDP elasticity of its square would become negative $\left(\beta_{2}<0\right)$.

Equation (1) is modified now through the disaggregation of the service sector $\left(y s_{t}\right)$ from the GDP:

$$
c_{t}=\beta_{0}+\beta_{1} y d_{t}+\beta_{2}\left(y d_{t}\right)^{2}+\beta_{3} y s_{t}+\varepsilon_{t}
$$


where now, $y d_{t}$ is the per capita GDP once services have been deducted, $y s_{t}$ is the service sector and its parameter is expected to be negative $\left(\beta_{3}<0\right) ; \varepsilon_{t}$ is the new error term.

This paper proposes the use of the autoregressive distributed lag (ARDL) methodology developed by Pesaran and Shin (1998), and Pesaran et. al. (2001). The advantages of the ARDL model are basically that one can work with either I(1) or I(0) variables and that serial correlation and endogeneity problems are easily removed when long-run and short-run components are simultaneously taken with appropriate lags (Pesaran and Shin 1998).

Following the ARDL methodology, after unit root tests have been carried out, Equation (2) can be written in an unrestricted error correction form once optimal lags through a model selection such as Akaike information criterion have been determined:

$$
\begin{gathered}
\Delta c_{t}=\alpha_{0}+\sum_{i=1}^{p} \alpha_{1 i} \Delta c_{t-i}+\sum_{i=1}^{p} \alpha_{2 i} \Delta y d_{t-i}+\sum_{i=1}^{p} \alpha_{3 i} \Delta\left(y d_{t-i}\right)^{2}+\sum_{i=1}^{p} \alpha_{4 i} \Delta y s_{t-i} \\
+\lambda_{1} c_{t-1}+\lambda_{2} y d_{t-1}+\lambda_{3}\left(y d_{t-1}\right)^{2}+\lambda_{4} y s_{t-1}+e_{t}
\end{gathered}
$$

The bounds testing approach is, then, used to examine the long-run parameters $\left(\lambda_{1}, \lambda_{2}, \lambda_{3}, \lambda_{4}\right)$ for the possibility of cointegration among the variables of interest (see Pesaran et al. 2001 for details). If cointegration exists the final step is to rewrite Equation (3) in the form of an error correction model, where ec is the error term:

$$
\begin{aligned}
& \Delta \Delta c_{t}=\pi_{0}+\sum_{j=1}^{p} \pi_{1 j} \Delta c_{t-i}+\sum_{j=1}^{p} \pi_{2 j} \Delta y d_{t-i}+\sum_{j=1}^{p} \pi_{3 j} \Delta\left(y d_{t-i}\right)^{2}+\sum_{j=1}^{p} \pi_{4 j} \Delta y s_{t-i} \\
& \quad+\psi e c_{t-1}+\xi_{t}
\end{aligned}
$$

\section{Data}

The empirical analysis uses annual data between 1940 and 2014. The data on $\mathrm{CO}_{2}$ emissions are collected from the Carbon Dioxide Information Analysis Center (CDIAC) (https://cdiac.essdive.lbl.gov). GDP is measured in constant dollars of 2011 stemming from the Maddison Project Database (https://ggdc.net/maddison). Service GDP is expressed as a 2011 index taken from both the Estadísticas Históricas de España Fundación BBVA and the Instituto Nacional de Estadística (http://ine.es). All variables were transformed into per capita terms. Total population was gathered from the Maddison Project Database.

\section{Results}

As a first approach to data analysis one can observe Figure 1 that shows the evolution of per capita $\mathrm{CO}_{2}$, per capita GDP without services and per capita services GDP. There is a certain comovement among the three series. Nevertheless, for the last years of the period it is interesting to see how per capita $\mathrm{CO}_{2}$ drops at a faster rate meanwhile both variables, per capita GDP with and without services smoothly decrease and eventually start to rise.

The ARDL allows to work with stationary and I (1) variables but not with variables of superior order. That is the reason why one has to test for unit roots first. The Modified Augmented Dickey Fuller (MADF) test (Table 1) takes into account possible structural breaks either in trends and/or intercepts.

The innovational outlier (IO) of Table 1, which considers that a structural break occurs gradually, indicates that only $c_{t}$ is an I(1) variable whereas the rest of them are stationary or I (0). However, the additive outlier (AO), which assumes that a structural break occurs immediately, shows that all variables are I(1). 
Figure 1. Evolution of $\mathrm{CO}_{2}$, GDP without services and services GDP.

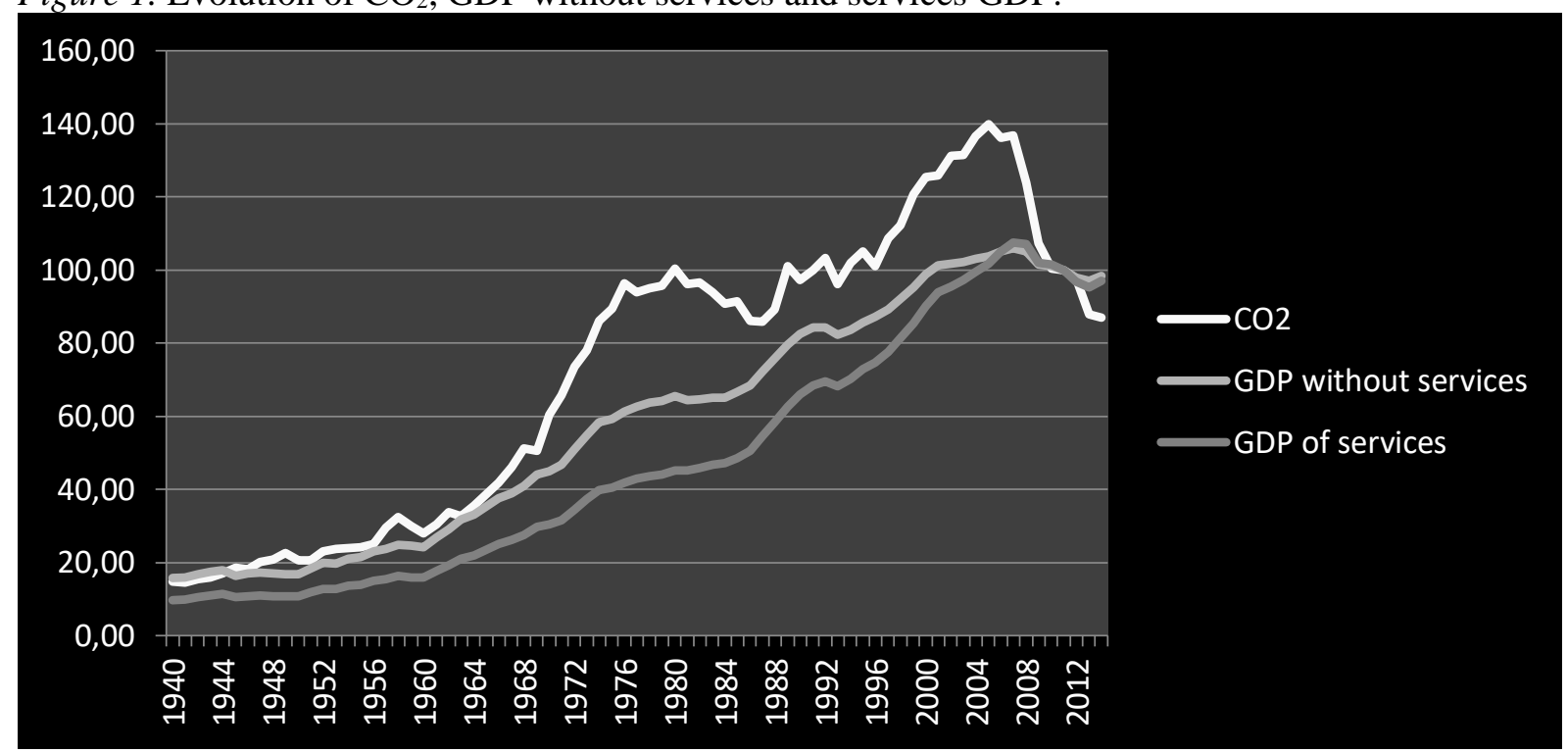

Notes: All the three variables are expressed in per capita terms and in 2011 indices.

Table 1. Unit root test of Modified Augmented Dickey-Fuller (MADF)

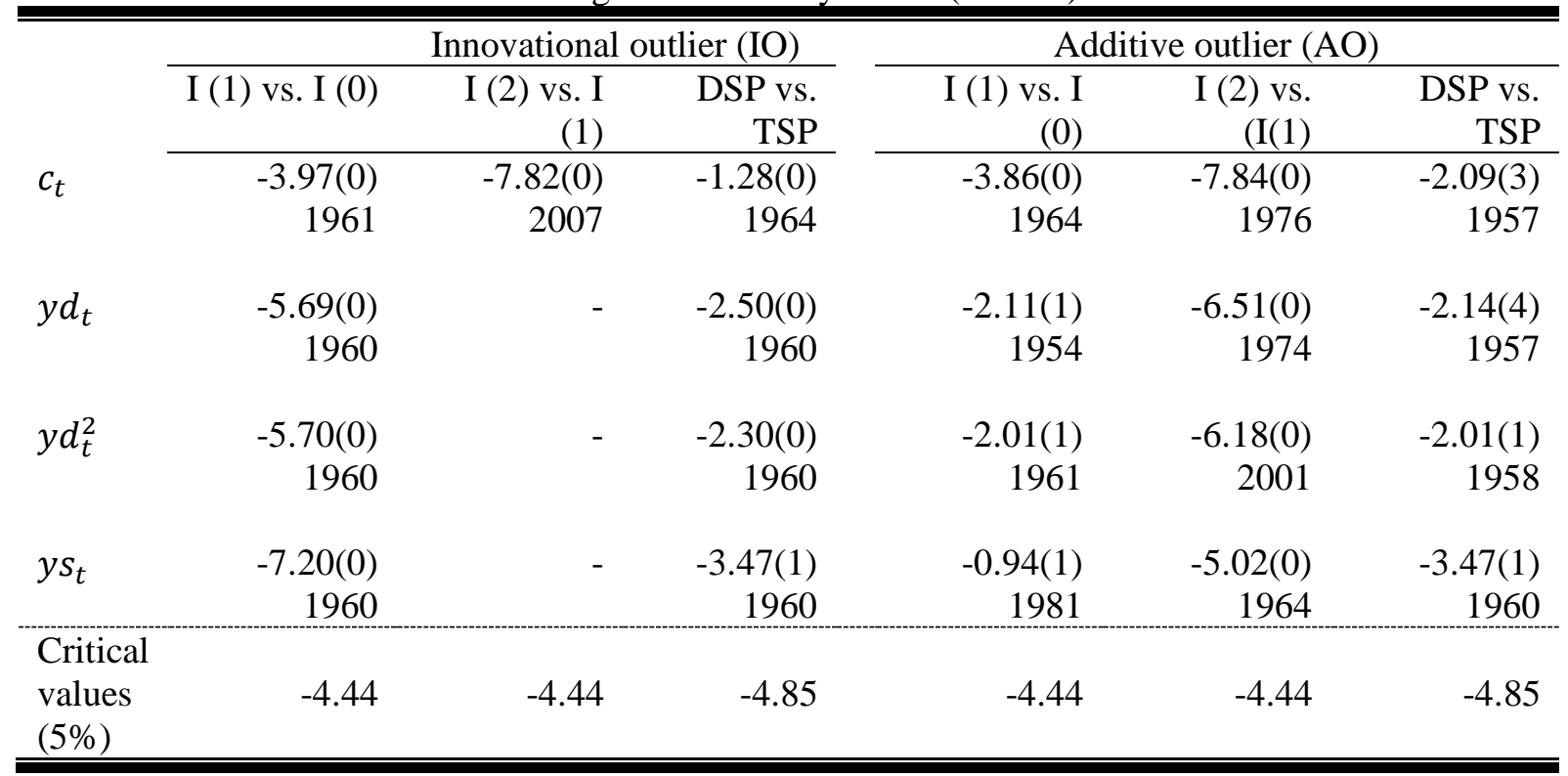

Notes: All variables are in natural logarithms: $c_{t}$ (per capita $\left.\mathrm{CO}_{2}\right) ; y d_{t}$ (per capita GDP without services); $y d_{t}^{2}$ (the square of per capita GDP without services); $y s_{t}$ (per capita services GDP).The numbers between parentheses are the lags used in the modified augmented Dickey-Fuller (MADF) test in order to remove serial correlation in the residuals. Break dates are below the MADF statistics. DSP stands for difference stationary process or I(1), and TSP means trend stationary process or $\mathrm{I}(0)$ with a trend process.

Equation (3) is now used to analyse the long-run relationship among the variables $\left(c, y d, y d^{2}\right.$ $y s$ ) where the optimum lag order is chosen through the Akaike Information Criterion (Table 2). The ARDL bounds test indicates that there exists cointegration among the four variables (Table 2).

In order to strengthen the results of the bounds test, the Engle and Granger cointegration test is also applied. Table 3 reports both the Engle-Granger tau-statistic (t-statistic) and the normalized autocorrelation coefficient (z-statistic) for residuals obtained by using $c_{t}$ as the dependent variable in a single cointegrating equation. Both statistics clearly reject the null of no cointegration reinforcing the results of the ARDL bounds test. 
Table 2. Optimal lag order and ARDL bounds test.

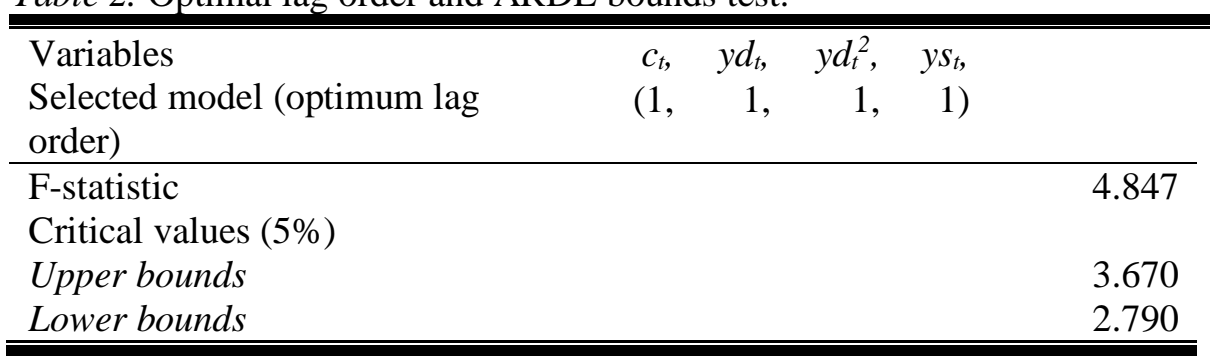

Table 3. Engle and Granger cointegration test

\begin{tabular}{lcccc}
\hline \hline Dependent variable & tau-statistic & Probability & z-statistic & Probability \\
\hline$c_{t}$ & -4.29 & 0.046 & -154.44 & 0.000 \\
\hline \hline
\end{tabular}

Notes: The null hypothesis is of no cointegration. This test is applied in a single equation for which $c_{t}$ is the dependent variable. Critical values are from MacKinnon (1996).

Table 4. ARDL long-run results 1940-2014.

\begin{tabular}{crrrrrrrr}
\hline & \multicolumn{3}{c}{ Standard model } & & \multicolumn{3}{c}{ Modified model } \\
& Coefficient & $t$-statistic & $P$-value & & Coefficient & $t$-statistic & $P$-value \\
\cline { 2 - 5 } \cline { 5 - 8 }$\alpha_{0}$ & -24.384 & -2.407 & 0.018 & & -19.369 & & \\
$y_{t}$ & 5.151 & 2.111 & 0.038 & & - & - & \\
$y_{t}^{2}$ & -0.252 & -1.727 & 0.018 & & - & - & \\
$y d_{t}$ & & & & & 3.012 & 1.292 & 0.201 \\
$y d_{t}^{2}$ & & & & & -0.002 & -0.011 & 0.992 \\
$y s_{t}$ & & & & & -1.525 & -3.638 & 0.000 \\
\hline \hline
\end{tabular}

Notes: Sensitivity analysis and other statistics are provided in the error correction models.

The long-run estimates for the carbon dioxide Kuznets curve, named here as the standard model (Table 4), prove the existence of the inverted-U shape relationship. The turning point from which more per capita GDP means less $\mathrm{CO}_{2}$ emissions is calculated from the expression,

$$
\hat{y}=\exp \left(-\hat{\beta}_{2} / 2 \hat{\beta}_{3}\right)
$$

It is reached at 27,446 US\$ (2011 base), which approximately would correspond to per capita GDP for year 1998. Now, if one looks at the modified model where service sector is deducted from total per capita GDP and this enters as an individual variable, then, the environmental Kuznets curve does not any longer exist. Neither signs nor significance back up the phenomenon just stated. However, the service sector reveals itself as an influential variable in the long run. The variable is significant at $1 \%$ level and its negative value indicates that for each $1 \%$ increase in magnitude of services activities the $\mathrm{CO}_{2}$ emissions diminish $1.5 \%$. This is a larger effect that the one found by Friedl and Getzner $2003(0.36 \%)$ who included the GDP variable, but without subtracting the services GDP.

The EKC, in the error correction model (Table 5), does not either exist which is logical given that it is a long-run concept. The service sector in the short-run contributes to more $\mathrm{CO}_{2}$ emissions. It needs time effects to change its structure and reverse its influence. The error correction term confirms the existence of cointegration and shows that any short-run disequilibrium is adjusted by an amount of $18 \%$ a year. All diagnostic tests in Table 5 and Figures 2-3 (stability tests) support the validity of the modified model. 
Table 5. Error correction model results (short-run).

\begin{tabular}{lrrr}
\hline \hline & Coefficient & t-statistic & P-value \\
\cline { 2 - 4 }$\Delta y d_{t-1}$ & -5.466 & -2.591 & 0.012 \\
$\Delta y d_{t}^{2}$ & 0.353 & 2.698 & 0.008 \\
$\Delta y s_{t}$ & 0.513 & 2.223 & 0.029 \\
$e c_{t-1}$ & -0.183 & -5.070 & 0.000 \\
\hline Statistics & & & \\
\hline S.E. of regression & & 0.049 & \\
AIC & & -3.085 & \\
F-statistics & 217.442 & \\
Serial correlation & & & 0.688 \\
Heteroskedaticity & & & 0.420 \\
Normality & & & 0.977 \\
Functional form & & & 0.831 \\
\hline \hline
\end{tabular}

Notes: Variables starting with $\Delta$ mean differenced once; variables lagged one period are expressed as $t-1$; ec is the error correction term. S.E. is the standard errors. AIC represents Akaike information criterion. Serial correlation is based on the Lagrange multiplier test; heteroskedaticity on Breusch and Pagan; normality on Jarque Bera test and functional form or misspecification on Ramsey's reset test.

Figure 2. Cumulative sum of recursive residuals test (CUSUM)

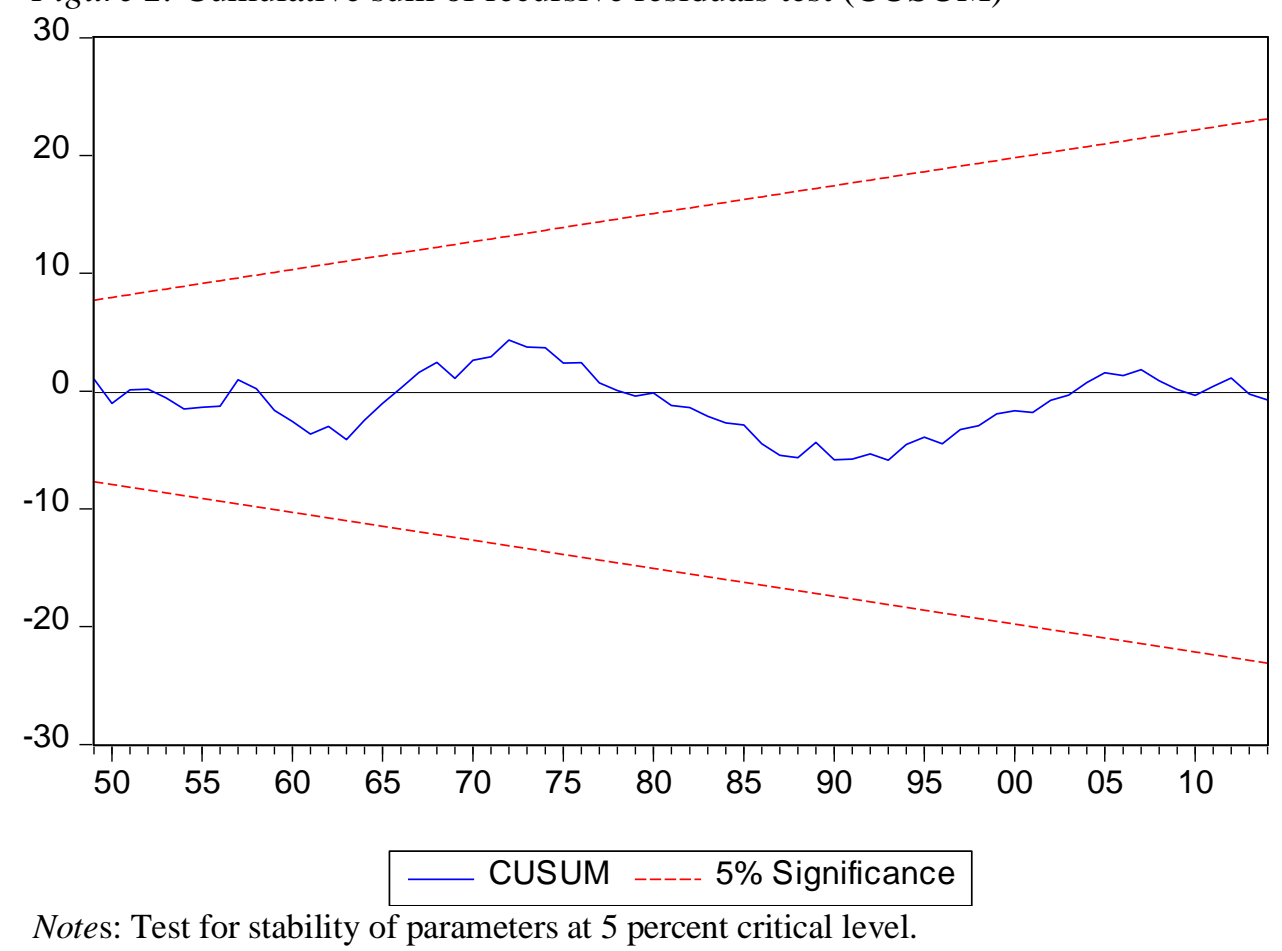

The causality analysis (Table 6) favours a unidirectional relationship going from either the GDP without services and services GDP to $\mathrm{CO}_{2}$. A bi-directional causality is also revealed between both the GDP without services and the services GDP which makes sense. These results along with those of the ARDL model confirm that the service sector becomes fundamental in order to reduce $\mathrm{CO}_{2}$ emissions.

\section{Concluding remarks}

This paper shows the influence of the service sector on the evolution of $\mathrm{CO}_{2}$ emissions. To this end it focuses on a different approach to the environmental Kuznets curve model where the 
added value of services is isolated from total GDP. This analysis has been applied to Spain in the period between 1940 and 2014. The results reinforce the idea that the evolution of the economy towards a service-driven economy leads to the reduction of $\mathrm{CO}_{2}$ emissions. In this sense, the service sector appears to be an essential sector. Economic growth which is mostly led by service activity is part of the solution and not the cause of more pollution. Binding $\mathrm{CO}_{2}$ emission targets for the most polluting sub-sectors in services such as transportation should be a priority for any sectoral environmental policy. In doing so, advisable environmental policies should promote research, design and development (RD\&D), energy innovation, more specific sector regulations, taxation and a general transition to renewable sources where governments take the lead for example for the electrification of their vehicles so that the rest of the economy follows.

Figure 3. Cumulative sum of squares of recursive residuals (CUSUMSQ).

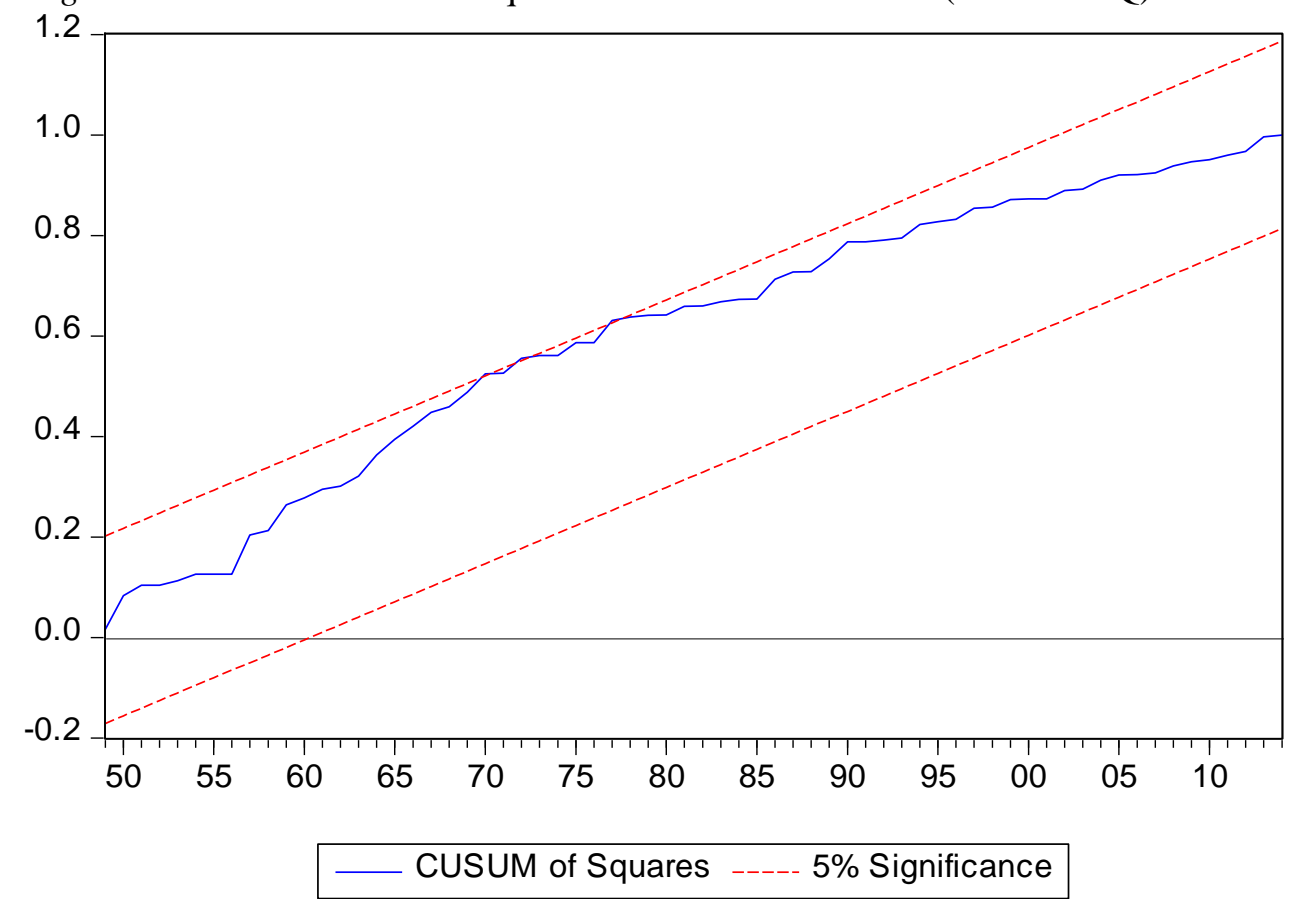

Notes: Test for stability of parameters at 5 percent critical level.

Table 6. Pairwise Granger Causality tests

\begin{tabular}{lrr}
\hline \hline \multicolumn{1}{c}{ Null hypothesis } & F-statistic & $P$-value \\
\hline$y d$ does not Granger cause $c$ & 7.350 & 0.001 \\
$c$ does not Granger cause $y d$ & 0.477 & 0.622 \\
\hline$y d^{2}$ does not Granger cause $c$ & 7.760 & 0.000 \\
$c$ does not Granger cause $y d^{2}$ & 0.767 & 0.468 \\
\hline$y s$ does not Granger cause $c$ & 5.209 & 0.008 \\
$c$ does not Granger cause $y s$ & 1.922 & 0.154 \\
\hline$y d^{2}$ does not Granger cause $y d$ & 5.394 & 0.063 \\
$y d$ does not Granger cause $y d^{2}$ & 5.828 & 0.005 \\
\hline$y s$ does not Granger cause $y d$ & 2.870 & 0.064 \\
$y d$ does not Granger cause $y s$ & 2.615 & 0.081 \\
$y s$ does not Granger cause $y d^{2}$ & 2.633 & 0.079 \\
$y d^{2}$ does not Granger cause $y s$ & 2.375 & 0.100 \\
\hline \hline
\end{tabular}




\section{Acknowledgments}

I gratefully acknowledge the comments and suggestions of the referees. Financial support from the Spanish Ministry of Science, Innovation and Universities (RTI2018-100983-B-I00), and Universitat Jaume I (UJI-B2019-53) are also appreciated. Finally, I want to express my gratitude to Juan Carlos Cuestas for his hints on an earlier draft.

\section{References}

Balsalobre-Lorente D., and Alvarez-Herranz, A. (2016a) Economic growth and energy regulation in the environmental Kuznets curve, Environmental Science and Pollution Research, 23, 16478-16494.

Balsalobre-Lorente D., and Alvarez-Herranz, A. (2016b) An approach to the effect of energy innovation on environmental Kuznets curve: an introduction to inflection point, Bulletin of Energy Economics, 4, 224-233.

Dinda, S. (2004) Environmnetal Kuznets curve: a survey, Ecological Economics, 49, 431-455.

Estadísticas Históricas de España: Siglos XIX-XX. Carreras A., Tafunell X. (coordinadores) Fundación BBVA, Segunda edición 2005 (1348-50).

Friedl, B., and Getzner, M. (2003) Determinants of $\mathrm{CO}_{2}$ emissions in a small economy, Ecological Economics, 45, 133-148.

Grossman, G., and Krueger, A., (1991) Environmental impacts of North American free trade agreement, National Bureau of Economic Analysis, Technical Report.ns

Kijima, M., Nishide, K., and Ohyama, A. (2010) Economic models for environmental Kuznets curve: a survey, Journal of Economics and Dynamics Control, 34, 1187-1201.

Kuznets, S. (1955) Economic growth and income inequality, American Economic Review, 45, $1-28$.

Panayotou, T. (1993) Empirical tests and policy analysis of environmental degradation at different stages of economic development, Working Paper WP238, Technology and Employment Programme, ILO, Geneva.

Pasten, R., and Figueroa B. E. (2012) The environmental Kuznets curve: a survey of the theoretical literature, International Review of Environmental and Resource Economics, 6, 195-224.

Pesaran, M. H., and Shin, Y. (1998), An autoregressive distributed lag modelling approach to cointegration analysis, in: Strom, S. (Eds.), Econometrics and Economic Theory, in 20th Century: The Ragnar Frisch Centennial Symposium. Cambridge University Press, Cambridge.

Pesaran, M. H., Shin, Y., and Smith, R. J. (2001) Bounds testing approaches to the analysis of level relationships, Journal of Applied Econometrics, 16, 289-326.

Sarkodie, S. A., and Strezov, V. (2019) A review on environmental Kuznets curve hypothesis using bibliometric and meta-analysis, Science of the Total Environment, 649, 128-145.

Shafik, N., and Bandyopadhyay, S. (1992) Economic growth and environmental quality: time series and cross-country evidence, Background Paper for World Development Report 1992, World Bank, Washington, DC.

Shahbaz, M., and Sinha, A. (2019) Environmental Kuznets curve for $\mathrm{CO}_{2}$ emissions: a literature survey, Journal of Economic Studies, 46, 106-168. 